\title{
Environmental impacts of food consumption and nutrition: where are we and what is next?
}

\author{
Thomas Nemecek $^{1}$ - Niels Jungbluth ${ }^{2} \cdot$ Llorenç Milà i Canals $^{3} \cdot$ Rita Schenck $^{4}$
}

Received: 1 February 2016 / Accepted: 17 February 2016 / Published online: 2 March 2016

(C) Springer-Verlag Berlin Heidelberg 2016

\begin{abstract}
Purpose This article introduces the special issue "LCA of nutrition and food consumption" and 14 papers selected from the Ninth LCA Food Conference in San Francisco in October 2014.

Literature overview The scientific literature in the field of food LCA has increased more than ten times during the last 15 years. Nutrition has a high contribution to the total environmental impacts of consumption. Agricultural production often dominates the impacts, but its importance depends on the type of product, its production mode, transport, and processing. Local or domestic products reduce transports, but this advantage can be lost if the impacts of the raw material production are substantially increased. Diets containing less meat tend to be more environmentally friendly. Several studies concluded that respecting the dietary recommendations for a healthy diet would reduce the overall environmental impacts in the developed countries, although this is not a universal conclusion.
\end{abstract}

Responsible editor: Mary Ann Curran

Thomas Nemecek

thomas.nemecek@agroscope.admin.ch

1 Agroscope, Institute for Sustainability Sciences, 8046 Zurich, Switzerland

2 ESU-services Ltd., 8050 Zurich, Switzerland

3 UNEP-Division of Technology, Industry and Economics, 75441 Paris, France

4 Institute for Environmental Research and Education, Vashon, WA 98070, USA
Contribution of this special issue Eight papers analyze the environmental impacts of catering and in-house food consumption and impacts on sectoral and national levels; four papers presents tools and methods to better assess the impacts of nutrition and to implement the results in practical decisionmaking. Finally, two contributions analyze the impacts of food waste and reduction options.

Challenges for the environmental assessment of nutrition (i) Comprehensive assessment. Most studies only analyze climate impacts, although data, methods, and tools are readily available for a more comprehensive analysis. (ii) Assessment of sustainability. The social dimension remains the weakest pillar. (iii) Data availability is still an obstacle, but significant progress has been made in recent years. (iv) Lack of harmonization of methodologies makes comparisons among studies difficult. (v) Land use. Enhanced consideration of land use impacts on biodiversity and ecosystem services is required in LCA. (vi) Defining the functional unit including nutritional aspects, food security, and health needs further work. (vii) Consumer behavior. Its impacts are still little assessed. (viii) Communication of the environmental impact assessment results to stakeholders including policy-makers and consumers needs additional efforts.

Research needs and outlook (i) Development of holistic approaches for the assessment of sustainable food systems, (ii) assessment of land use related impacts and inclusion of ecosystem services, (iii) exploration of LCA results for policy support and decision-making, (iv) investigation of food consumption patterns in developing and emerging countries, and (v) harmonization of databases.

Keywords Diet · Environmental impacts · Food consumption $\cdot$ Life cycle assessment $\cdot$ Nutrition . Sustainability 


\section{Introduction}

Food production is responsible for a major part of the environmental impacts in the developed countries (Tukker et al. 2006, 2011) and its share of overall impacts could be even more important in the developing countries, where the absolute impacts per capita are smaller and therefore the relative contribution of food could gain importance.

The environmental consequences of food production and consumption have gained a lot of attention in recent years. From the first applications of life cycle approaches to agriculture in the 1970s, it has successively evolved to the consideration of the whole food chain. As more and more LCA data on single food products became available, some studies considered the impacts of different meals or full diets. More recently, environmental considerations were aligned with the analysis of other aspects of nutrition such as health (Tilman and Clark 2014) or other wider sustainability aspects including the social and economic dimensions.

Starting in 1996, the "LCA food" conferences dealt with the analysis of the environmental impacts of the agri-food sector. The conference has evolved from a small meeting of several dozens of specialists to a well-established conference with a wide audience of 300 to 400 participants for the last three conferences. The Ninth International Conference on Life Cycle Assessment in the Agri-Food Sector was held in San Francisco, USA, on 8-10 October 2014. A special focus was laid on the environmental assessment of the consequences of food production and consumption during the conference. This special issue of the International Journal of Life Cycle Assessment presents 14 selected papers from this conference focusing on the following topics:

- Environmental impacts of consumption patterns, diets, and nutrition

- Methodology, data, and tools for the analysis of nutrition and food consumption

- Environmental impacts of food losses

This article gives an introduction into this special issue and is structured as follows: The next section presents an overview of the developments in the field of LCA of nutrition and food consumption over the last decades. It is followed by a brief overview of the 14 articles in this issue. Section 4 presents the challenges that practitioners are facing when they assess the environmental consequences of food consumption. The last section presents the research needs and priorities and finishes with an outlook to the expected future developments.

\section{Literature overview}

\subsection{The development of environmental assessment in the agri-food sector}

The first life cycle approaches to the analysis of food production with a focus on primary energy demand date back to the 1970s (Darnay and Nuss 1971; Pimentel 1973). About 17 years ago an overview of LCA studies dealing with food production and consumption resulted in a list of 200 publications, which even included a range of grey literature reports (Jungbluth 1999). At that time, the research was often focused on Europe and many studies dealt mainly with the primary agricultural production of basic food items. The research field has grown rapidly and such a comprehensive overview related to scientific articles, conference contributions, grey literature, and internal studies related to LCA in the agri-food sector is not feasible anymore. The number of publications in the field rose dramatically. For example, a search in Scopus for publications with the keywords "life cycle assessment" and "agriculture" or "food" showed a more than tenfold increase from 25 in the year 2000 to 287 in 2014.

Several studies are related to methodological issues of LCA for agricultural products, representing particular challenges. In agriculture, many emissions cannot be directly measured like end-of-pipe emissions, but they have to be estimated through models given their diffuse nature. Emissions strongly depend on climate, soil, and topography and can vary considerably, even within the same region. The differences of production in different regions, using different agricultural practices or the variability between individual farms are highlighted in several research papers. Other LCA studies look on the full life cycle of a single product from farm to fork. In the last years, more and more research has also been carried out in order to investigate complex products such as ready-to-eat meals (Büsser and Jungbluth 2009, 2011; Davis et al. 2010). Another part of the literature relates to newly developed type of food products (Aiking 2011; Smetana et al. 2015) or improved food processing.

Today LCA studies related to food are published for and in all regions of the world. Nevertheless, the majority of studies still come from Europe and North America. There are very few studies for eastern Europe, Russia, Central Asia, and Africa. Between 2010 and 2014, $57 \%$ of the publications in the field of agricultural and food LCA originated from Europe, $20 \%$ from North America, and $12 \%$ from Asia.

Articles in scientific journals nowadays tend to focus on more specific aspects, e.g., the impact assessment for water use or fishing in order to be accepted for publication. LCA case studies, representing mere applications of the LCA methodology, are often not innovative enough to be accepted either for a $\mathrm{PhD}$, or for journal publication. Many of such studies 
published as grey literature, e.g., by consultancies or food companies.

With the availability of LCA data for all types of food items, it is also possible to carry out more complex analyses. Organizational LCA studies look on all food products purchased, e.g., by an international food company, distributor, canteen operator, or restaurant. Full diets and food consumption patterns are also investigated through detailed LCA studies.

The environmental impacts of food consumption patterns can be investigated from different perspectives, with different goals and basic data on the quantity (or expenses) of food consumed, for example:

- food consumption compared to total impacts of final consumption based on input-output analysis and expenditure statistics,

- food produced and imported for the market in a given country (based on production and foreign trade statistics),

- food sold by a distributor, restaurant, or canteen (internal documentation of the company),

- food purchased by customers (reported in questionnaires with information for the mass or expenses),

- food eaten by customers (reported in questionnaires),

- dietary recommendations for customers (theoretical calculations based on nutritional values of different products), and

- nutritional value of single food items as part of a diet.

\subsection{Lessons learnt from research}

We now summarize the main results of LCA studies for food consumption.

\subsubsection{Contribution of different life cycle phases}

For most simple food products, the further stages such as processing, transportation, packaging, and distribution are generally of lower importance (Foster et al. 2006). Agricultural production dominates many of the impacts. This is particularly true for impacts related to land use such as biodiversity and soil quality, impacts related to the use of pesticides (aquatic and terrestrial ecotoxicity), and impacts of the use of fertilizers and nutrient losses (N and $\mathrm{P}$ ) in general. Eutrophication is dominated by the agricultural phase. This phase is also important for acidification related to ammonia emissions, although emissions from transport and combustion of fossil fuels also contribute a significant share of this impact. About $70 \%$ of the global water use by humans is caused by agriculture (The Crop Site 2015), primarily for irrigation. Thus, in food products coming from irrigated land, irrigation will dominate the water use. There are many examples of rivers no longer meeting the sea because of anthropogenic withdrawals. On the other hand, processing, storage, transport, and distribution of food products play an important role for impacts which are more related to industrial processes. Cumulative energy demand, global warming potential, photochemical ozone formation, and ozone depletion are typical impact categories where the processes after the farm gate are significant. The contribution of the agricultural phase further depends on several factors. Generally, food products such as meat have a high impact per product unit in the agricultural phase, and this phase largely dominates the food impacts. The impacts of processing, storage, distribution, and transport are generally of less importance (Alig et al. 2012). A notable exception are products transported by air freight, since this mode of transport has a very high impact.

For some beverages such as mineral water the packaging and transportation causes a major part of impacts. This holds also true for products with a high water content, e.g., canned beans. Impacts of food products with a high degree of processing are sometimes dominated by the food industry stage.

Production in heated greenhouses has high environmental impacts and therefore seasonal products are generally environmentally preferable, unless they come from areas with water scarcity (Stoessel et al. 2012) or the greenhouse is heated with clean renewable energy.

\subsubsection{Local and alternative food supply systems}

Many consumers are sensitive to the origin of the food they purchase and consume. Preference is often given to local, regional, or domestic production. In addition to aspects such as cultural value and food security, regional specialties and support for regional and domestic economies, environmental considerations play an important role. It is argued that local production needs shorter transport distances and is therefore preferable and the concept of "food miles" has been put forward some years ago as an indicator for environmental preferability. However, a growing number of LCA studies showed that local or domestic production does not necessarily have advantages over imports from an environmental point of view, and that transport mode is more important than transport distance.

The absolute contribution of transport depends on the transport distance, the mode of transport, and the type of transport (e.g., cooled or uncooled). Generally the impacts per tonnekilometer increase in the order freight $\operatorname{ship}<$ rail $<$ road $<<$ air freight. The relative importance of the transport depends further on the impacts per product unit for the production (see 2.2.1). For example, fruits and vegetables have high fresh yields per area unit and generally low impacts per product unit. For these product categories, because production environmental impacts are low, the relative impact of transport is significant (Robertson 
et al. 2014; Stoessel et al. 2012) while, e.g., for meat products it has a much lower relative relevance.

With the exception of transport by air freight and very long distances, the mode of agricultural production is more important in determining whether domestic or imported products are preferable (Alig et al. 2014; Bystricky et al. 2014b; Webb et al. 2013).

Alternative food systems such as community supported agriculture, food processing, and distribution directly from farms have gained popularity in the last decades and have been shown to have better resource efficiency in some cases (Markussen et al. 2014; Schramski et al. 2013) and were also proposed as solutions to reduce food waste (Caputo et al. 2014). However, compared to industrial large-scale production, such systems often lack efficiency, so that in many cases they have higher impacts on the environment than standard systems (Kulak et al. 2015).

\subsubsection{Environmental impacts of different diets}

Animal products and in particular meats have higher impacts than food originating from plants (Pelletier et al. 2011; Tilman and Clark 2014). Raising and feeding animals introduces an additional trophic level in the food chain, and each trophic level leads to losses of energy and nutrients, thus reducing the efficiency of the production. The agricultural production of feedstuffs and animal husbandry make a significant contribution to the overall impact (Alig et al. 2012; Jungbluth 2000). There are, however, significant differences among the animal products. Per kilogram of edible protein, the impacts generally decrease in the order beef $>$ pork $>$ poultry meat (de Vries and de Boer 2010; Eshel et al. 2014; Flachowsky 2011; Tilman and Clark 2014). The differences in environmental impacts run in parallel with different feed conversion ratios and cycle lengths. Dairy products have considerably lower impacts than beef per kilogram of protein, which are of the order of magnitude of poultry meat. When comparing animal species, one should bear in mind that only roughage feeders such as ruminants can feed on grasslands, which make up two thirds of the agricultural areas worldwide, while monogastric species like swine and poultry cannot make use of it. Fish may have either relatively low or very high impacts, depending on whether they originate from aquaculture or wild catch, how efficient the aquaculture production is and how rare a caught species is, influences the fuel use for its catching.

These differences in environmental impacts of various food items imply differences in the environmental impacts of whole diets. A growing literature has been devoted to the study of these impacts.

Hallström et al. (2015) suggested dietary change as a way to reduce environmental impacts of human nutrition. They identified a potential of up to $50 \%$ for GHG reduction and land use demand in areas with affluent diets. The reduction of meat consumption played a major role. The highest reduction potentials were identified for vegan and vegetarian diets, but the reduction potential of a diet according to the recommendations for healthy nutrition was also significant.

The environmental impacts of the Average Danish Diet (ADD) were compared with the New Nordic Diet (NND), which was defined as containing $35 \%$ less meat, more whole-grain products, nuts, fruit, and vegetables as well as locally grown food in season, and over $75 \%$ organic produce (Saxe 2014). The NND proved to have lower environmental impacts in all categories. Reducing meat consumption and avoiding long-distance imports were favorable in the NND compared to ADD. Organic products showed advantages or drawbacks as compared to conventional products, depending on the impact category and the food product. Combining the NND with short transport distances and organic produce decreased the advantages of the changed diet and the local production.

Heller et al. (2013) reviewed 32 studies using an LCA framework to assess the environmental impacts of diets or meals. Studies with an efficiency-oriented (production) perspective and a demand-restraint (consumption) perspective are distinguished. They discussed ways to include nutritional aspects into the analysis based on diet quality indices, nutrient profiling, and epidemiologic studies.

Auestad and Fulgoni (2015) reviewed 31 articles about the environmental and economic impacts of dietary patterns. The authors identified a need for a more complete assessment of environmental, social and economic impacts and called for a strong inter-disciplinary collaboration to achieve this goal.

The effects of meeting dietary requirements on GHG emissions were evaluated by Macdiarmid et al. (2012). An optimized diet respecting acceptability constraints resulted in a reduction of $36 \%$ of the GHG emissions related to the nutrition of the population in UK. The change would imply a shift from meat, high fat- and sweet food towards more fruit and vegetables as well as starchy food. Meat consumption in the alternative diet would be reduced to $60 \%$ of current dietary levels, that of red meat to $48 \%$, while the consumption of dairy products would remain at a similar level. The study showed that a diet with lower GHG emissions would be possible without increasing costs to consumers.

Vieux et al. (2013) analyzed GHG emissions associated with self-selected French diets and their relationship with the nutritional quality. The energy density, the mean adequacy ratio (MAR), and the mean excess ratio (MER) were used as criteria. MAR is an indicator for good nutritional quality, while MER indicates bad nutritional quality. MAR was positively correlated and MER negatively correlated to GHG emissions. The authors concluded that although the selfselected diets with high nutritional quality contained large amounts of plant-based food products, they did not have the lowest GHG emissions. 
Masset et al. (2014) analyzed 363 food items, representing the most commonly consumed products in France. The environmental criteria were GHG emissions, acidification, and eutrophication. The nutritional quality was characterized by the ratio of the score for nutritional adequacy (SAIN) and the score for disqualifying nutrients (LIM). The ratio SAIN/LIM was used as an indicator of nutritional quality. Meat, fish, eggs, and dairy products had the higher environmental impacts, while starchy products, legumes, fruits, and vegetables had the lowest impacts. High nutritional quality was correlated to lower GHG emissions and lower prices.

Tom et al. (2015) investigated the energy and water consumption and the greenhouse gas emissions from different diets in the US population. Reducing caloric intake to the recommended levels reduced the impacts on energy and water use as well as climate, while the change of the diet to the 2010 USDA Dietary Guidelines led to an increase of energy use by $38 \%$, blue water footprint by $10 \%$, and GHG emissions by $6 \%$. The authors explain this by the USDA dietary recommendations, leading to higher consumption of fruits, vegetables, dairy, and fish/seafood, which have relatively high energy and water demand and GHG emissions per calorie. Furthermore, the consumption of added sugars, solid fats and oils is reduced; these food components have relatively low impacts per calorie.

Environmental impacts found in the literature, e.g., for the $\mathrm{kg} \mathrm{CO}_{2}$-eq per person and day can vary considerably between different studies. This can be partly explained by different geographical or situational boundaries. Differences in data sources or allocation rules can also influence the results. Furthermore, household structure and consumer behavior have a major influence on the results (Saner et al. 2015). Some overview studies look more systematically at all the relevant differences among such studies, e.g., Fantin et al. (2014) for single products or Heller et al. (2013) for dietary choices.

The growing evidence stemming from LCA studies is increasingly considered in dietary recommendations (e.g., SGE (2014)).

\subsubsection{Food waste}

Food that is not consumed increases the impact per unit of consumed food as all its upstream impacts are allocated to the food consumed. The contribution of food waste to the increase of environmental impacts of the food sector has come into the public focus during the last years. FAO (2011) estimated that roughly one third of the edible parts of food gets lost or wasted globally, corresponding to 1.3 billion tons per year. The wastage at the consumer level is higher in industrialized than in developing countries, while in the latter pre- and post-harvest losses are dominating. Data on food waste are generally sparse and highly uncertain.

Grizzetti et al. (2013) estimated that $2.7 \mathrm{Tg}$ of nitrogen per year are lost at the global scale due to food waste at consumption. Heller and Keoleian (2015) showed that food losses contribute $1.4 \mathrm{~kg} \mathrm{CO}_{2}$ eq per capita and day to the overall carbon footprint of the average US diet.

The role of packaging in the reduction of food losses and related environmental impacts is elaborated by several studies (e.g., Grant et al. 2015). The environmental impacts of packaging cannot be analyzed by considering merely the impacts of packaging production, transport, reuse, recycling, or disposal, but must also include the evaluation of the effects on food quality and storage life. Nothing will be gained for the environment, if food waste is considerably increased by reducing packaging.

Different treatment options for food waste have been analyzed in the literature (Chiew et al. 2015; Eriksson et al. 2015; Vandermeersch et al. 2014), but this topic is not further discussed here, since it is out of scope for this article.

Bernstad Saraiva Schott and Andersson (2015) analyzed the potentials of food waste minimization in households to reduce environmental impacts in a case study in southern Sweden. They noted that it is important to distinguish between avoidable and unavoidable food waste. Their analysis of the waste composition indicated that only $35 \%$ of the household food waste was avoidable. Nevertheless they found that reducing food waste could considerably reduce environmental impacts, which proved to be far more beneficial than an optimized incineration or anaerobic digestion of food waste.

Bernstad Saraiva Schott and Cánovas (2015) estimated in their review that the potential saving of avoiding food waste lies between 0.8 and $4.4 \mathrm{~kg} \mathrm{CO}_{2}$ eq per $\mathrm{kg}$ of waste. The emissions from avoided food production dominated the results. In addition, consumer transport and end-consumer food preparation can have a large impact as well. They stated considerable differences in the methodologies applied, which makes the comparison of the different studies tedious.

Generally the impacts of food losses are higher if they occur later in the food chain, since all processes occurring before that stage are wasted.

\section{The contribution of this special issue}

\subsection{Environmental impacts of consumption patterns, diets, and nutrition}

\subsubsection{Catering and in-house food consumption}

Pulkkinen et al. (2015) present a study about the communication of carbon footprints in the hospitality sector. Other criteria than carbon footprint are not considered, due to lack of data. 
"Climate Choice" labels were given for meals with lower than average climate impacts. These labels raised the awareness of the restaurant staff and of consumers, but the effect of the short campaign remained limited; a long-term concept for informing the customers would therefore be needed. Other aspects such as taste, attractiveness, and price were more important decision criteria for customers than the carbon footprint.

Ribal et al. (2015) describe an optimization model (goal programming), which was used to design meals for school canteens by taking into account nutritional, climate change, and economic aspects. Reductions in carbon footprints and prices of meals were possible while maintaining the nutritional properties of the meals. It is feasible to define meals with simultaneously lower carbon footprint and lower price, thus avoiding trade-offs between these two criteria. The tool allows school canteens to improve the sustainability of their meals.

The environmental impacts and carbon footprint of 240 Swiss canteens were analyzed by Jungbluth et al. (2015). The global warming potential of food purchases was about four times higher than the direct impacts due to the operation of the canteens. The most impacting product groups were meat and dairy products. The authors derived recommendations for the reduction of the overall environmental impacts. Among them was the reduction of food waste in the canteens, avoidance of vegetables from heated greenhouses and airfreighted products, as well as the reduction of the average amount of meat per meal. For achieving these goals, cooperation between suppliers, canteen operators, canteen owners, and guests is necessary.

Saner et al. (2015) present a "FoodPrint" of households. They used data from the Swiss household budget survey and applied multiple linear regressions based on generalized linear models to quantify food and beverage demand of individual households. Carbon footprints of individual household of a single Swiss municipality were calculated from these data. The authors found a large variability of results, which was however smaller than the variability in the climate impacts of housing or mobility of these households. The differences were primarily explained by different consumption patterns of meat and dairy products. The paper highlights the importance of analyzing the behavior of individual households, since large differences exists, which imply a large improvement potential.

\subsubsection{Analysis at sectoral and national level}

Sonesson et al. (2015) analyzed the supply chains of six commodities, i.e., milk, cheese, beef, pork, chicken, and bread, from a Swedish region and presented the pork chain as an example. Three scenarios addressing different environmental goals (reduce local impact on ecosystems, optimize plant nutrient use and supply, and reduce climate impact and energy use) were investigated. Their consequences for products and systems from the food safety, sensory quality, animal welfare, consumer appreciation, and (for primary production only) cost perspectives were assessed. Reductions of up to $54 \%$ for climate change and up to $45 \%$ for marine eutrophication could be achieved by improving supply chains. A high productivity was important to achieve large reductions.

How many people could be potentially supported by the agricultural area available in The Netherlands and which diet would make such nutrition possible? This question was addressed in a study by van Kernebeek et al. (2015), using a linear programming model. As expected, reducing the proportion of animal products (i.e., shift to plant-based diet) would allow to nourish a larger population. However, a minimum amount of about $12 \%$ of animal products should be maintained in the diet, in order to allow the use of land which is unsuitable for crop production. On this land, mainly dairy products would be produced, with beef being a co-product of the dairy sector.

van Dooren and Aiking (2015) analyzed the historical Dutch diet and calculated its climate, land use, and health impacts (assessed by a health score). This traditional diet was optimized by linear programming in order to reduce its environmental impact and to increase the health score. The optimized diet was compared to a Mediterranean and the New Nordic Diet showing that it had the same nutritional characteristics in respect to health, while it resulted in a lower environmental impact, expressed by a combined greenhouse gas emission and land use score. The authors argue that an optimized diet based on the traditional diet would have a better cultural acceptability to the Dutch population than a foreign diet.

Tyszler et al. (2015) optimized diets for Dutch women between 31 and 50 years by means of linear programming. The purpose was to identify diets meeting the nutritional requirements, but with lower environmental impacts than the present diet. As a further criterion, a penalty score expressed the deviation from the current diet. The authors concluded that simply following the dietary guidelines does not guarantee an improved environmental profile. It was possible to find less restrictive solutions than vegetarian or vegan diets, still satisfying all nutritional requirements and with less environmental impact than the current one.

\subsection{Methodology, data, and tools}

A simplified web-based tool should enable small and medium size enterprises (SMEs) in the food and drink sector to calculate the environmental impacts of their products. It has been developed in the European project SENSE (Ramos et al. 2015). For this purpose, cooperation with and data entry by suppliers is necessary. Data for key environmental performance indicators must be collected to calculate ten 
environmental impact category indicators. The SENSE tool can be used for (i) environmental impact assessment of the product, (ii) food chain hot spot identification, (iii) comparison of hypothetical or real improvement scenarios, (iv) assessment of the environmental impact development over the years, (v) benchmarking opportunity for the companies, and (vi) a business to business communication strategy.

The exposure of humans to pesticides by the food route is a matter of public debate, but is generally ignored in agricultural LCAs. Fantke and Jolliet (2015) present a framework for characterizing human toxicological impacts associated with pesticides applied to agricultural crops in the frame of life cycle impact assessment. Intake by residues on food varies widely between the different active ingredients, but crop characteristics and pesticide application times have a strong influence as well. Intake fractions and characterization factors for human toxicity according to the USETOX method were made available for 875 active ingredients and six crops.

Stylianou et al. (2015) developed a novel Combined Nutritional and Environmental Life Cycle Assessment (CONE-LCA) framework that evaluates and compares in parallel the environmental and nutritional effects of food items or diets. Beneficial and detrimental impacts of the nutrition on health were included in the assessment of human health impacts (measured in disability adjusted life years, DALYs). The method was illustrated by the example of adding one serving of fluid milk to the present American adult diet. This led to an increase of environmental impacts on human toxicity of the total diet, but this was more than outweighed by the beneficial impacts on health. This effect was even increased, when the milk addition was iso-calorically substituted for sugar-sweetened beverages, which have negative health effects. This methodological extension moves LCA nearer to the social impact assessment.

van Zanten et al. (2015) present a method to account for the suitability of land for the cultivation of food crops. The land use ratio (LUR) is defined as the maximum amount of human digestible protein (HDP) derived from food crops on the land used to cultivate the animal feed over the amount of HDP in the animal product. The LUR was 2.08 for laying hens, 2.10 for milk production on sandy soil, where arable crops also can be grown, and 0.67 for milk production on peat soil, not suited for arable crops. LUR values $<1.0$ show animal production systems contributing to global food security, as they allow an increase in the overall protein production.

\subsection{Environmental impacts of food losses}

Eberle and Fels (2015) analyzed the environmental impacts of German food consumption and food losses. The losses made up between 11 and $17 \%$ of the environmental impacts of inhouse food consumption; for out-of-home food consumption they were even more important with 28 to $33 \%$ losses, depending on the impact category. The life cycle phases agriculture and consumption caused the highest impacts; together they were responsible for over $87 \%$ of the total environmental burdens. Animal products had a relatively high share in the total impacts. The study showed that food production and consumption as well as food losses along the value chain are important drivers of environmental impacts.

Gruber et al. (2015) showed that substantial reduction of environmental impacts could be achieved through the reduction of food losses. Main food losses occur in the consumer phase. Three different types of consumer behavior were modeled: baseline, environmentally conscious and careless. This resulted in considerable differences in the total life cycle impacts, which shows how the environmental impact of food consumption can be reduced by an environmentally conscious consumer. Important improvement potentials have been identified during shopping, in the reduction of electricity consumption for food storage or preparation and by avoiding wasting of food. The authors emphasize the importance of including the consumer stage in LCAs of food products.

\subsection{Main achievements at the conference and in this special issue}

The following main steps forward have been made during the LCA Food 2014 conference. Parts of them are reflected by the selection of papers presented in this special issue. Key achievements from the point of view of the authors are the following:

- Methodological developments such as emission modeling and impact assessment (toxicity impacts of pesticides, salinization, odor impacts, soil quality)

- Assessment of land use and land use change impacts and more detailed assessment of the food production potentials of land

- Assessment of the impacts of food consumption at home and out of home, including aspects of consumer behavior

- Quantification of environmental impacts of nutrition at national or global levels

- An increasing number of studies focused on the analysis of food waste, related environmental impacts and mitigation options

- Progress in the development of tools and databases for analysis and decision-making

- Communication of environmental and sustainability aspects to different stakeholders

- Studies showing the benefits of cooperation between stakeholders in the food chain. 


\section{Challenges for the environmental assessment of nutrition}

While performing assessments of the environmental impacts of food consumption and nutrition, the practitioner faces a number of challenges. Some of the main challenges are described in the following.

Environmental impacts considered There are three ways to address the environmental impacts of nutrition and food consumption: with a single environmental issue (e.g., carbon or water footprint), by discussing several midpoint impact categories separately (e.g., ILCD) or by weighting several impact categories into a final single score at the endpoint (e.g., $\mathrm{ReCiPe}$, ecological scarcity). Each of these approaches has pros and cons and the choice depends on the goal and scope of each study. The use of a single environmental issue is the easiest approach. It needs less data in the life cycle inventory analysis as several types of emissions or resource uses need not be accounted for. The interpretation of results is much easier as there is one type of result and no diverging results for several indicators. Many studies focus on a single environmental issue, which is mostly the climate impact assessed by the carbon footprint methodology (Auestad and Fulgoni 2015; Heller et al. 2013). This choice is driven by the high relevance and attention to the issue in the public debate, the relatively important share of the food sector in greenhouse gas emissions, and the good availability of data. The contributions to this special issue confirm this finding. While carbon footprint is undoubtedly of high environmental relevance and gives a first important insight into the impact of nutrition on the environment, it is clearly insufficient to describe the full range of environmental impacts of food systems. Some studies assess the use of fossil energy only, which was found to be a good indicator for the total environmental impact in general, but notably with the main exception of agricultural products (Huijbregts et al. 2010). Agricultural production has a number of environmental impacts not related to fossil energy use or climate impacts. Important examples are the impacts on biodiversity, soil quality, water resources, nutrient emissions to water (mainly nitrogen and phosphorus), or toxic impacts on ecosystems through pesticides and other pollutants such as heavy metals. Jungbluth et al. (2011) showed that the nutrition of the Swiss population is responsible for $12 \%$ of the nonrenewable energy use, while it generates $17 \%$ of the global warming potential and $29 \%$ of the total environmental impact assessed by the Swiss ecological scarcity method 2006 . Similar trends were found in a European study (Tukker and Jansen 2006). These examples clearly show that considering merely fossil energy or greenhouse gas emissions is not sufficient to address the range of environmental impacts of nutrition, since the impacts related to agricultural production in general dominate the impacts of nutrition (Foster et al.
2006). ISO standards 14040 and 14044 (ISO 2006a, b) require the assessment of all relevant environmental impacts by discussing results for several impact categories (e.g., according to ENVIFOOD (2012)) and the tools and databases to implement this are available. Thus, we see an important challenge to consider all relevant environmental impacts also in the assessment of diets and food styles.

Assessing different sustainability dimensions Applications of a life cycle sustainability assessment in the food sectori.e., considering the environmental, economic, and social impacts altogether - remain very rare. The social dimension is a particularly weak point of this assessment, where reliable databases and a well-accepted methodology even after more than 20 years of discussion are still widely missing. A strong investment in further development is needed to achieve a practicable methodology for the food sector and to fill this gap (Smith and Barling 2014). Development of guidelines in the last years (UNEP 2009) and the build-up of relevant databases (Benoit-Norris et al. 2012) laid a basis for further progress in this field. Agriculture being at the base of human development and often at the base of many global value chains, there is a growing interest among food companies to ensure adequate prosperity of their suppliers (often smallholder farmers) in order to secure their own supply base. In this sense, developing adequate indicators that can show progress in the social dimension through the products' life cycles is of paramount importance. Trade-offs between the different sustainability dimensions are quite common, so that adequate compromises are needed. For example, production systems with costly pollution prevention or intensive animal production systems may be efficient from an environmental point of view, but may be less favorable in respect to animal welfare (Alig et al. 2012); some low input farming systems may also generate low environmental impacts but also low returns and profitability for farmers, which may result in low social development scores. In addition to environmental, social, and economic issues, sustainability assessments of food systems should measure attainment of the outcomes of such systems, i.e., food security and nutrition (avoiding both undernourishment and overconsumption, which lead to new health issues such as noncommunicable diseases) (Westhoek et al. 2014).

Data requirements A human diet is composed of many food products and each food product may be composed of many different ingredients. Each ingredient may have a different degree of processing, and the raw materials used may originate from different countries. Therefore, one faces a high data demand and level of complexity, when trying to assess the environmental impacts of the diet of a whole population. The environmental impacts of a food product depend on the country of origin (Bystricky et al. 2014a; Webb et al. 2013) and on the production system (Payen et al. 2015). Publicly 
available LCI databases such as ecoinvent (ecoinvent Centre 2014) contain limited data regarding the agricultural and food sectors and allow differentiation of production systems and countries of origin only in some cases. Recent database initiatives such as the French AGRI-BALYSE (Koch and Salou 2013), the Dutch Agri-Footprint (Blonk 2014), or the US LCI (NREL 2012) partly remedy this situation. Private consultants also offer databases covering a large range of food products in several countries (JRC 2015). Thus, today a lot of different LCA databases for food products are available. Combining different databases, however, is problematic as they may use different methodological standards and background data. Many research groups also have their own database used in LCA studies. Large data gaps exist if one wants to distinguish the environmental impacts of several similar food items that can be found in the shop. In this context, methods to fill these data gaps for ingredients and food products of minor importance such as using direct proxies, upscaled proxies, averaged proxies (Milà i Canals et al. 2011), or extrapolation (Roches et al. 2010) offer feasible alternatives in many cases.

Methodological aspects System boundaries are defined based on the goals of the single study. As a minimum, the analysis of food consumption should cover the production chain up to the point of sale including agricultural production, processing, transport, and distribution. Studies often focus on the agricultural phase and ignore further stages, because they only address the improvement in this stage. However, if the downstream stages contribute significantly to the overall impact and differ between the products compared, such studies cannot address the full impacts of food production. Additional stages after the point of sale might be considered depending on the goal and scope of the analysis, e.g., home transportation, chilling, cooking, treatment of wastes, and effluents. However, for a broader analysis of household consumption, e.g., by input-output analysis, these aspects are not assigned directly to the field of food purchases as they are covered in other consumption domains such as mobility or energy use.

The inclusion of food waste at the different stages is highly relevant (see sections 2.2.4 and 3.3), but in practice it is often difficult to quantify because data cannot be collected directly from the stakeholders. Furthermore, waste during consumption depends on consumer behavior, which can be highly variable.

A further issue is the choice of an attributional or consequential modeling approach (EC-JRC-IES 2010). Within attributional modeling, there are other important choices, e.g., the allocation approach. The allocation principle (e.g., economic, mass, product properties, etc.) is a matter of debate, but within an LCA study, a consistent approach must be applied. Some food industry sectors propose a recommended methodology that can cover all their products in a harmonized way (e.g., IDF (2010), or sectors covered in the EC's Product Environmental Footprint, European Commission (2015)). Some LCA studies use consequential modeling to assess the overall impacts of a diet (e.g., Schmidt and Merciai 2014). In this case, the assumption on consequences, which normally cannot be observed directly, is quite relevant for the final results.

Link to land use Contrary to many other economic sectors, the food sector is strongly dependent on land use, with the main exception of seafood, which is of course dependent on sea area or volume. The availability of land with high suitability to agricultural production as well as water available for irrigation put a serious constraint on global and local food production (Fischer et al. 2010). Increasing the agricultural production area has strong environmental impacts; this constrained resource availability, compounded with the increased demand from the growing world population, challenges future agricultural production. Changes in food production systems or diets have consequences on other food systems or related sectors, such as biofuel production and vice versa. Direct and indirect land use change may have a strong effect on the impacts of food products and diets. UNEP-IRP (2014) assesses land as a resource and suggests several options to a sustainable land use, including: (i) Reducing excessive food consumption, notably by reducing food waste and shifting to more plant-based diets in high meat consuming countries. (ii) Restoration of degraded soils and avoiding building activities on fertile land. (iii) Promote research and extension of best agricultural practices to maintain soil quality, increase yield, and thus reduce pressure for deforestation. (iv) More efficient use of biomass and its substitutes through better cooperation to improve supply chains, better communication between manufacturers and consumers, enhanced international efforts toward global resource management (e.g., toward soil restoration), and a better framework for sustainable resource management at the scale of countries, regions, and cities. (v) Decoupling markets for food and fuel. In addition, certification schemes may play a significant role in driving the uptake of sustainable agriculture practices if coupled with performance indicators that demonstrate their positive effects through the value chain. Adequate indicators for land use impacts on biodiversity and ecosystem services are required (Koellner et al. 2013) to provide a basis to develop land use strategies, with enough granularity capable of differentiating sustainable agriculture practices such as those promoted by certification schemes.

Functions of food and choice of functional unit Assessing the environmental impacts of food products and nutrition is a complex issue, since food has to fulfill many functions. Human nutrition is the most obvious function, but the quantification of the contribution of a single food product to this 
function remains a challenge (Nicklas et al. 2014). The choice of the functional unit strongly depends on the goal and scope of the study and on the perspective applied (production or consumption perspective) with increasing complexity from the comparison of agricultural production methods to the evaluation of full diets (Heller et al. 2013). Kendall and Brodt (2014) compared several food products by using different functional units including mass, serving size, energy content, protein content, and a composite nutrient score. The environmental impacts vary considerably according to the choice of the functional unit, which was also found by Van Kernebeek et al. (2014). In addition to nutrition, food also has further functions and aspects such as taste, pleasure, aesthetics, cultural value, impact on health, local economy, etc. It is not possible to capture all these aspects in a single functional unit. Therefore, in each study, the considered functions should be clearly stated - together with the aspects that were not included - and the consequences of this choice should be discussed. Not only the intrinsic quality of a food product is relevant for the consumer's choice, but other aspects are too, including its origin (consumers often prefer locally produced or domestic food) and its mode of production (e.g., meat from production systems respecting animal welfare or fair-trade products). Ideally, these aspects should be evaluated in a comprehensive life cycle sustainability assessment.

Consumer behavior The environmental impacts of the diet strongly depend on consumer behavior. Which food products are consumed and the type of diet have a strong effect on the outcome as shown for example by Tilman and Clark (2014) and several contributions in this special issue (see Section 3). Food wasted at home can considerably increase the impacts on the environment (Gruber et al. 2015). The mode of preparing the food can create a large variability in environmental impact (Saner et al. 2015), in particular when considering the decreasing size of households and accordingly the smaller batches of food prepared. Cooking small amounts of food uses considerably more energy per kilogram than preparing larger amounts (Sonesson et al. 2003). Food storage at home can also have a strong influence on the energy use as well as on the generation of food waste. Due to higher mobility and changing eating habits, food is increasingly consumed out of home, which creates a new level of complexity. Thus data, e.g., on preparation and serving in restaurants are necessary in order to assess the full environmental impacts of food consumption.

Communicating environmental assessment results In practice, complex studies evaluating multiple environmental indicators and several dimensions of sustainability are difficult to communicate to consumers or other stakeholders in the food chain. To inform final consumers, the information must be reduced in a meaningful way in order to help them address the environmental impacts of their consumption patterns correctly and especially guiding them to consumption patterns causing less environmental impact (Finkbeiner 2014; Jungbluth et al. 2012). Trade-offs between indicators are regularly observed. Different methodologies are available which weight different types of environmental impacts and summarize them to a single score (e.g., Frischknecht et al. 2013; Goedkoop et al. 2009; Tukker et al. 2006). These methods consider a wide range of environmental impacts and ensure that the interpretation of results does not depend too much on the value choices of a single researcher. However, they apply the value system of the method developers and commissioners which is, e.g., based on user surveys or political regulations. According to the ISO standard 14044, "weighting shall not be used in LCA studies intended to be used in comparative assertions intended to be disclosed to be public." However, this requirement is a matter of debate. Depending on the goal and the target group, the need to present a single score result exists. Some institutions try to overcome this situation by further investigating the possibilities for single score weighting (e.g., the PEF guidelines of the EU, European Commission 2013), where normalization is a recommended step, while weighting to a single score can be applied optionally.

\section{Research needs and outlook}

A few key areas requiring improvement in the next years can be extracted from the discussions in the LCA Food 2014 Conference, mostly addressed in the sections above:

Development of holistic approaches for the assessment of sustainable food systems requires not only the development of the assessment of environmental, social, and economic impacts of such systems; on the output side, i.e., the functional unit, not only the provision of food but also food security itself, health, and nutrition should be considered. This latter aspect requires a proper consideration of consumption habits and lifestyles, which go beyond the assessment of food itself, but are of paramount importance to address key drivers of the lack of sustainability of food systems, such as food wastage and overconsumption.

In some of the environmental impacts being considered, such as those related to land and water use, there is already a marked tendency to incorporate the regional conditions in the assessment. This is in line with a need to incorporate potential effects at the landscape level, a consideration of scale that is commonly ignored in LCA (Milà i Canals and de Baan 2015). The growing interest for impacts on ecosystem services and biodiversity, and the use of LCA to inform policy makers and other stakeholders, justify exploration of possible links between landscape and conservation ecology approaches and the LCIA methods, which to some extent is already happening (Curran et al. 2016). 
The full potential of LCA as a tool to support policy making may only be realized with a proper exploration of how the results of LCA studies (usually at farm or field level) may be extrapolated to inform scenarios at the landscape level. Indeed, even if product comparisons may already inform the benefits of specific agricultural production techniques at the field level, policy will usually be designed to generate benefits or reduce impacts at higher scale. There is good potential to mainstream the use of LCA in the agricultural sector if its results are linked to the indicators being designed to inform targets in the Sustainable Development Goals (SDGs) endorsed by the United Nations in September 2015 (United Nations General Assembly 2015). In particular, LCA may inform which practices contribute to the environmental sustainability of agriculture (target 2.4).

In relation to the assessment of diets so far most studies focus on the investigation in developed countries. Food styles in these countries are often related to overconsumption and health issues due to this. But, in many countries of the world, people face problems due to insufficient supply of food. Impacts due to the present food supply in these countries and possible issues linked to providing a healthy and affordable diet to these populations should also be monitored. In this context, a better investigation of small-scale farming and local food supply with its challenges and opportunities is needed.

In-between the developed and developing countries are emerging societies with a rapidly changing and growing economy like China and India. With growing affluence, food consumption patterns are evolving towards including more animal-based products and thus also increased impacts. The challenge here is to guide development to a more sustainable future without increasing environmental impacts.

In terms of the data challenge, significant international initiatives are underway to bridge gaps; as with all other sectors, it is crucial that the required data are generated, documented, and stored in an interoperable manner, so initiatives do not remain unconnected but rather synergize with each other. The Global Network of Interoperable LCA Databases is attempting such goal. In the field of food LCA, in addition to the aspects of interoperability that are common to any LCA dataset (such as the nomenclature used for environmental and technical flows, or the metadata descriptors), the modeling criteria used may differ significantly between data sources. This must be addressed to enhance the usability of data beyond the databases and studies for which they were collected.

Another important issue is the communication of LCA results to consumers. What constitutes environmentally sound behavior in terms of diet is complex, and guidance should focus on the most important drivers of impact. Simplification of the messages to general rules is needed, but these rules need to be supported by scientific evidence and be applicable to the respective situation. The communication needs to be adapted to the target group, which implies various degrees of detail ranging from a full list of relevant single indicators to single scores. National guidance on nutrition is an area where LCA-based information is already being coupled with nutritional studies (e.g., in the Netherlands, the USA, see Merrigan et al. (2015)); these make use of recurrent evidence that some food groups or products are preferable over others both in terms of sustainability and nutrition (e.g., plant-based over excessive animal-based products). However, given the high economic stakes in the food sub-sectors, for LCA evidence to effectively influence policy and nutritional guidance, stronger links to higher level political objectives such as contribution to the UN's Sustainable Development Goals would be useful.

Agriculture and the food sector are key drivers of environmental and social impacts worldwide, but they may also hold the key for the contribution of the economy to reduced impacts, enhanced biodiversity and ecosystem services, and improved livelihoods. LCA and life cycle thinking more generally have the potential to identify more sustainable business models in food production and consumption systems. This paper and special issue provide some clear directions for the methodological research and implementation needs to achieve such more sustainable food systems.

Acknowledgments The authors warmly thank all contributors to this special issue and Mary Ann Curran and Moira Ledger for their support in the preparation of this issue.

Disclaimer The views expressed in this article are those of the authors and do not necessarily reflect those of the various affiliated organizations.

\section{References}

Aiking H (2011) Future protein supply. Trends Food Sci Technol 22:112120

Alig M, Grandl F, Mieleitner J, Nemecek T, Gaillard G (2012) Ökobilanz von Rind-, Schweine- und Geflügelfleisch. Agroscope ReckenholzTänikon ART, Zürich, 151 p

Alig M, Nemecek T, Bystricky M, Gaillard G (2014) Influence of site conditions and production system on the environmental impacts of domestic and imported cheese. In: Proc. 9th International Conference LCA of Food, 8-10 October 2014, San Francisco, pp 31-38

Auestad N, Fulgoni VL (2015) What current literature tells us about sustainable diets: emerging research linking dietary patterns, environmental sustainability, and economics. Adv Nutr Int Rev J 6:1936

Benoit-Norris C, Cavan DA, Norris G (2012) Identifying social impacts in product supply chains: overview and application of the social hotspot database. Sustainability 4:1946-1965

Bernstad Saraiva Schott A, Andersson T (2015) Food waste minimization from a life-cycle perspective. J Environ Manag 147:219-226

Bernstad Saraiva Schott A, Cánovas A (2015) Current practice, challenges and potential methodological improvements in environmental evaluations of food waste prevention - a discussion paper. Resour Conserv Recycl 101:132-142 
Blonk (2014) Agri-footprint: Methodology and basic principles. Blonk Agri-footprint BV, Gouda, NL

Büsser S, Jungbluth N (2009) LCA of Ready-to-serve bolognese lasagne packed in aluminium containers. ESU-services Ltd. commissioned by European Aluminium Foil Association e.V. (EAFA), Düsseldorf, $\mathrm{DE}$ and Uster, $\mathrm{CH}$

Büsser S, Jungbluth N (2011) LCA of ready-to-serve goulash soup packed in stand-up pouches. ESU-services Ltd. commissioned by European Aluminium Foil Association e.V. (EAFA), Düsseldorf, $\mathrm{DE}$ and Uster, $\mathrm{CH}$

Bystricky M, Alig M, Nemecek T, Gaillard G (2014a) Ökobilanz ausgewählter Schweizer Landwirtschaftsprodukte im Vergleich zum Import. Agroscope, Zürich. Agroscope Science, 2, $176 \mathrm{p}$

Bystricky M, Nemecek T, Alig M, Gaillard G (2014b) Challenges of comparing food and feed products from different countries of origin. In: Proc. 9th International Conference LCA of Food, 8-10 October 2014, San Francisco, pp 194-202

Caputo P, Ducoli C, Clementi M (2014) Strategies and tools for ecoefficient local food supply scenarios. Sustainability (Switzerland) 6:631-651

Chiew YL, Spångberg J, Baky A, Hansson PA, Jönsson H (2015) Environmental impact of recycling digested food waste as a fertilizer in agriculture - a case study. Resour Conserv Recycl 95:1-14

Curran MP et al (2016) How well does LCA model land use impacts on biodiversity? - a comparison with approaches from ecology and conservation. Environ Sci Technol. doi:10.1021/acs.est.5b04681

Darnay A, Nuss G (1971) Environmental impacts of Coca-Cola Beverage Containers. Midwest Research Institute for Coca-Cola USA

Davis J, Sonesson U, Baumgartner DU, Nemecek T (2010) Environmental impact of four meals with different protein sources: case studies in Spain and Sweden. Food Res Int 43:1874-1884

de Vries M, de Boer IJM (2010) Comparing environmental impacts for livestock products: a review of life cycle assessments. Livest Sci 128:1-11

Eberle U, Fels J (2015) Environmental impacts of German food consumption and food losses. Int J Life Cycle Assess. doi:10.1007/ s11367-015-0983-7(thisissue)

EC-JRC-IES (2010) International reference Life Cycle Data System (ILCD) Handbook - General guide for Life Cycle AssessmentDetailed guidance. First edition March 2010. Luxembourg, EUR 24708 EN, 417 p

ecoinvent Centre (2014) ecoinvent Data - The Life Cycle Inventory Data V3.1. Swiss Centre for Life Cycle Inventories, Dübendorf, Switzerland

ENVIFOOD (2012) ENVIFOOD Protocol: environmental assessment of food and drink protocol. European food sustainable consumption \& production round table, Draft Version 0.1, for Pilot Testing

Eriksson M, Strid I, Hansson PA (2015) Carbon footprint of food waste management options in the waste hierarchy — a Swedish case study. J Cleaner Prod 93:115-125

Eshel G, Shepon A, Makov T, Milo R (2014) Land, irrigation water, greenhouse gas, and reactive nitrogen burdens of meat, eggs, and dairy production in the United States. PNAS 111:11996-12001

European Commission (2013) Commission recommendation of 9 April 2013 on the use of common methods to measure and communicate the life cycle environmental performance of products and organisations. Brussels. 2013/179/EU, $210 \mathrm{p}$

European Commission (2015) The Product Environmental Footprint Pilots. http://ec.europa.eu/environment/eussd/smgp/pef pilots.htm. Accessed 21 December 2015

Fantin V, Scalbi S, Ottaviano G, Masoni P (2014) A method of improving reliability and relevance of LCA reviews: the case of life-cycle greenhouse gas emissions of tap and bottled water. Sci Total Environ 476-477:228-241
Fantke P, Jolliet O (2015) Life cycle human health impacts of 875 pesticides. Int J Life Cycle Asses. doi:10.1007/s11367-015-0910$\mathrm{y}$ (thisissue)

FAO (2011) Global food losses and food waste — extent, causes and prevention. FAO, Rome, 38 p

Finkbeiner M (2014) Product environmental footprint — breakthrough or breakdown for policy implementation of life cycle assessment? Int J Life Cycle Assess 19:266-271

Fischer G, Hizsnyik E, Prieler S, Wiberg D (2010) Scarcity and abundance of land resources: competing uses and the shrinking land resource base. FAO, Rome. SOLAW Background Thematic Report, TR02, $58 \mathrm{p}$

Flachowsky G (2011) Carbon-footprints for food of animal origin, reduction potentials and research need. J Appl Animal Res 39:2-14

Foster C, Green K, Bleda M, Dewik P, Evans B, Flynn A, Mylan J (2006) Environmental impacts of food production and consumption: a report for the Department for Environment, Food and Rural Affairs. DEFRA, London, $199 \mathrm{p}$

Frischknecht R, Büsser Knöpfel S (2013) Ökofaktoren Schweiz 2013: gemäss der Methode der ökologischen Knappheit. Methodische Grundlagen und Anwendung auf die Schweiz. Bundesamt für Umwelt, Bern. Umwelt-Wissen no. 1330, 256 p

Goedkoop M, Heijungs R, Huijbregts MAJ, De Schryver A, Struijs J, van Zelm R (2009) ReCiPe 2008 - a life cycle impact assessment method which comprises harmonised category indicators at the midpoint and the endpoint level. First edition. Report I: Characterisation

Grant T, Barichello V, Fitzpatrick L (2015) Accounting the impacts of waste product in package design. Procedia CIRP 2015:568-572

Grizzetti B, Pretato U, Lassaletta L, Billen G, Garnier J (2013) The contribution of food waste to global and European nitrogen pollution. Environ Sci Pol 33:186-195

Gruber LM, Brandstetter CP, Bos U, Lindner JP, Albrecht S (2015) LCA study of unconsumed food and the influence of consumer behavior. Int J Life Cycle Assess. doi:10.1007/s11367-015-0933-4(thisissue)

Hallström E, Carlsson-Kanyama A, Börjesson P (2015) Environmental impact of dietary change: a systematic review. J Clean Prod 91:1-11

Heller MC, Keoleian GA (2015) Greenhouse gas emission estimates of U.S. dietary choices and food loss. J Ind Ecol 19:391-401

Heller MC, Keoleian GA, Willett WC (2013) Toward a life cycle-based, diet-level framework for food environmental impact and nutritional quality assessment: a critical review. Environ Sci Technol 47: 12632-12647

Huijbregts MAJ, Hellweg S, Frischknecht R, Hendriks HWM, Hungerbühler K, Hendriks AJ (2010) Cumulative energy demand as predictor for the environmental burden of commodity production. Environ Sci Technol 44:2189-2196

IDF (2010) A common carbon footprint approach for dairy. The IDF guide to standard lifecycle assessment methodology for the dairy sector. Bulletin of the International Dairy Federation 445/2010

ISO (2006a) ISO 14040 — environmental management - life cycle assessment - principles and framework

ISO (2006b) ISO 14044 —environmental management-life cycle assessment-requirements and guidelines

JRC (2015) LCA Resources Directory. Joint Research Centre of the EU. http://eplca.jrc.ec.europa.eu/ResourceDirectory/index.xhtml. Accessed 20.11.2015

Jungbluth N (1999) Case Studies, Research Groups and Results of LCA's for Food Products - Ökologische Beurteilung des Bedürfnisfeldes Ernährung: Arbeitsgruppen - Methoden - Stand der Forschung Folgerungen. Eidgenössische Technische Hochschule, Zürich. Umweltnatur- und Umweltsozialwissenschaften

Jungbluth N (2000) Umweltfolgen des Nahrungsmittelkonsums: Beurteilung von Produktmerkmalen auf Grundlage einer modularen Ökobilanz. Werkstattreihe Nr. 123. Öko-Insitut e.V. Verlag, Freiburg, Germany 
Jungbluth N, Büsser S, Frischknecht R, Flury K, Stucki M (2012) Feasibility of environmental product information based on life cycle thinking and recommendations for Switzerland. J Clean Prod 28: $187-197$

Jungbluth N, Keller R, König A (2015) ONE TWO WE-life cycle management in canteens together with suppliers, customers and guests. Int J Life Cycle Assess. doi:10.1007/s11367-015-09828(thisissue)

Jungbluth N, Stucki M, Leuenberger M, Nathani C (2011) Environmental impacts of Swiss consumption and production - a combination of input-output analysis with life cycle assessment. Federal Office for the Environment FOEN, Bern. Environmental Studies, $171 \mathrm{p}$

Kendall A, Brodt SB (2014) Comparing alternative nutritional functional units for expressing life cycle greenhouse gas emissions in food production systems. In: Proc 9th International Conference LCA of Food, 8-10 October 2014, San Francisco, pp 628-633

Koch P, Salou T (2013) AGRIBALYSE ${ }^{\circledR}$ : METHODOLOGY. Version 1.1

Koellner T et al (2013) UNEP-SETAC guideline on global land use impact assessment on biodiversity and ecosystem services in LCA. Int J Life Cycle Assess 18:1188-1202

Kulak M, Nemecek T, Frossard E, Chable V, Gaillard G (2015) Life cycle assessment of bread from several alternative food networks in Europe. J Clean Prod 90:104-113

Macdiarmid JI, Kyle J, Horgan GW, Loe J, Fyfe C, Johnstone A, McNeill G (2012) Sustainable diets for the future: can we contribute to reducing greenhouse gas emissions by eating a healthy diet? Am J Clin Nutr 96:632-639

Markussen MV, Kulak M, Smith LG, Nemecek T, Østergård H (2014) Evaluating the sustainability of a small-scale low-input organic vegetable supply system in the United Kingdom. Sustainability (Switzerland) 6:1913-1945

Masset G, Soler LG, Vieux F, Darmon N (2014) Identifying sustainable foods: the relationship between environmental impact, nutritional quality, and prices of foods representative of the french diet. J Acad Nutr Diet 114:862-869

Merrigan K, Griffin T, Wilde P, Robien K, Goldberg J, Dietz W (2015) Designing a sustainable diet. Science 350:165-166

Milà i Canals L, de Baan L (2015) Chapter 11: land use. In: Hauschild M, Huijbregts M (eds) Life cycle impact assessment. LCA Compendium-The Complete World of Life Cycle Assessment. Springer, Dordrecht, The Netherlands, pp 197-222

Milà i Canals L et al (2011) Approaches for addressing life cycle assessment data gaps for bio-based products. J Ind Ecol 15:707-725

Nicklas TA, Drewnowski A, O'Neil CE (2014) The nutrient density approach to healthy eating: challenges and opportunities. Publ Health Nutr 17:2626-2636

NREL (2012) U.S. Life Cycle Inventory Database. National Renewable Energy Laboratory

Payen S, Basset-Mens C, Perret S (2015) LCA of local and imported tomato: an energy and water trade-off. J Clean Prod 87:139-148

Pelletier N et al. (2011) Energy Intensity of Agriculture and Food Systems. In: Gadgil A, Liverman DM (eds) Annu Rev Environ Resour 36:223-246

Pimentel D (1973) Food production and the energy crisis. Science 182: 443-449

Pulkkinen H, Roininen T, Katajajuuri JM, Järvinen M (2015) Development of a climate choice meal concept for restaurants based on carbon footprinting. Int J Life Cycle Assess. doi:10.1007/ s11367-015-0913-8(thisissue)

Ramos S et al (2015) SENSE tool: easy-to-use web-based tool to calculate food product environmental impact. Int J Life Cycle Assess. doi: 10.1007/s11367-015-0980-x(thisissue)

Ribal J, Fenollosa ML, García-Segovia P, Clemente G, Escobar N, Sanjuán N (2015) Designing healthy, climate friendly and affordable school lunches. Int J Life Cycle Assess. doi:10.1007/s11367-0150905-8(thisissue)

Robertson K, Garnham M, Symes W (2014) Life cycle carbon footprint of the packaging and transport of New Zealand kiwifruit. Int J Life Cycle Assess 19:1693-1704

Roches A, Nemecek T, Gaillard G, Plassmann K, Sim S, King H, Canals LMI (2010) MEXALCA: a modular method for the extrapolation of crop LCA. Int J Life Cycle Assess 15:842-854

Saner D, Beretta C, Jäggi B, Juraske R, Stoessel F, Hellweg S (2015) FoodPrints of households. Int J Life Cycle Assess. doi:10.1007/ s11367-015-0924-5(thisissue)

Saxe H (2014) The New Nordic Diet is an effective tool in environmental protection: it reduces the associated socioeconomic cost of diets. Am J Clin Nutr 99:1117-1125

Schmidt JH, Merciai S (2014) Life cycle assessment of the global food consumption. In: Huizenga D (ed) Proc 9th International Conference on Life Cycle Assessment in the Agri-Food Sector (LCA Food 2014), San Francisco, USA, 8-10 October 2014, pp 1224-1233

Schramski JR, Jacobsen KL, Smith TW, Williams MA, Thompson TM (2013) Energy as a potential systems-level indicator of sustainability in organic agriculture: case study model of a diversified, organic vegetable production system. Ecol Model 267:102-114

SGE (2014) FOODprints ${ }^{\circledR}$ — Tipps zum nachhaltigen Essen und Trinken. Schweizerische Gesellschaft für Ernährung SGE. Bern, Switzerland

Smetana S, Mathys A, Knoch A, Heinz V (2015) Meat alternatives: life cycle assessment of most known meat substitutes. Int J Life Cycle Assess 20:1254-1267

Smith J, Barling D (2014) Social impacts and life cycle assessment: proposals for methodological development for SMEs in the European food and drink sector. Int J Life Cycle Assess 19:944-949

Sonesson U, Janestad H, Raaholt B (2003) Energy for preparation and storing of food - models for calculation of energy use for cooking and cold storage in households. SIK, Gothenburg. SIK-Rapport 709, $67 \mathrm{p}$

Sonesson UG et al (2015) Paths to a sustainable food sector: integrated design and LCA of future food supply chains: the case of pork production in Sweden. Int J Life Cycle Assess. doi:10.1007/ s11367-015-0969-5(thisissue)

Stoessel F, Juraske R, Pfister S, Hellweg S (2012) Life cycle inventory and carbon and water foodprint of fruits and vegetables: application to a swiss retailer. Environ Sci Technol 46:3253-3262

Stylianou KS, Heller MC, Fulgoni VL III, Ernstoff AS, Keoleian GA, Jolliet O (2015) A life cycle assessment framework combining nutritional and environmental health impacts of diet: a case study on milk. Int J Life Cycle Assess. doi:10.1007/s11367-015-09610 (thisissue)

The Crop Site (2015) Growing more food with less water. http://www thecropsite.com/focus $/ 5 \mathrm{~m} / 50 /$ growing-more-food-with-less-waterimproving-water-usage-in-agriculture. Accessed 7 October 2015

Tilman D, Clark M (2014) Global diets link environmental sustainability and human health. Nature 515:518-522

Tom MS, Fischbeck PS, Hendrickson CT (2015) Energy use, blue water footprint, and greenhouse gas emissions for current food consumption patterns and dietary recommendations in the US. Environ Syst Decis. doi:10.1007/s10669-015-9577-y

Tukker A et al (2011) Environmental impacts of changes to healthier diets in Europe. Ecol Econ 70:1776-1788

Tukker A et al. (2006) Environmental Impact of Products (EIPRO). Analysis of the life cycle environmental impacts related to the final consumption of the EU-25. Technical Report, 139 p.

Tukker A, Jansen B (2006) Environment impacts of products - a detailed review of studies. J Ind Ecol 10:159-182

Tyszler M, Kramer G, Blonk H (2015) Just eating healthier is not enough: studying the environmental impact of different diet scenarios for 
Dutch women (31-50 years old) by linear programming. Int J Life Cycle Assess. doi:10.1007/s11367-015-0981-9(thisissue)

UNEP-IRP (2014) Assessing global land use - balancing consumption with sustainable supply. United National Environment Programme (UNEP) International Resource Panel (IRP), $46 \mathrm{p}$

UNEP (2009) Guidelines for social life cycle assessment of products. United Nations Environment Programme, $104 \mathrm{p}$

United Nations General Assembly (2015) Transforming our World: the 2030 Development Agenda for Sustainable Development. New York, $35 \mathrm{p}$

van Dooren C, Aiking H (2015) Defining a nutritionally healthy, environmentally friendly, and culturally acceptable Low Lands Diet. Int J Life Cycle Assess. doi:10.1007/s11367-015-1007-3(thisissue)

Van Kernebeek HRJ, Oosting SJ, Feskens EJM, Gerber PJ, De Boer IJM (2014) The effect of nutritional quality on comparing environmental impacts of human diets. J Clean Prod 73:88-99

van Kernebeek HRJ, Oosting SJ, van Ittersum MK, Bikker P, de Boer IJM (2015) Saving land to feed a growing population: consequences for consumption of crop and livestock products. Int J Life Cycle Assess. doi:10.1007/s11367-015-0923-6(thisissue) van Zanten HHE, Mollenhorst $\mathrm{H}$, Klootwijk CW, van Middelaar CE, de Boer IJM (2015) Global food supply: land use efficiency of livestock systems. Int J Life Cycle Assess. doi:10.1007/s11367-0150944-1(thisissue)

Vandermeersch T, Alvarenga RAF, Ragaert P, Dewulf J (2014) Environmental sustainability assessment of food waste valorization options. Resour Conserv Recycl 87:57-64

Vieux F, Soler LG, Touazi D, Darmon N (2013) High nutritional quality is not associated with low greenhouse gas emissions in self-selected diets of French adults 1-3. Am J Clin Nutr 97:569-583

Webb J, Williams AG, Hope E, Evans D, Moorhouse E (2013) Do foods imported into the UK have a greater environmental impact than the same foods produced within the UK? Int J Life Cycle Assess 18: $1325-1343$

Westhoek H, Ingram J, van Berkum S, Milà i Canals L, Lomax J, Herrick J, Hajer M (2014) A food system approach for the identification of opportunities to increase resource use efficiency. In: Proc 9th International Conference LCA of Food, 8-10 October 2014, San Francisco, pp 1505-1511 